
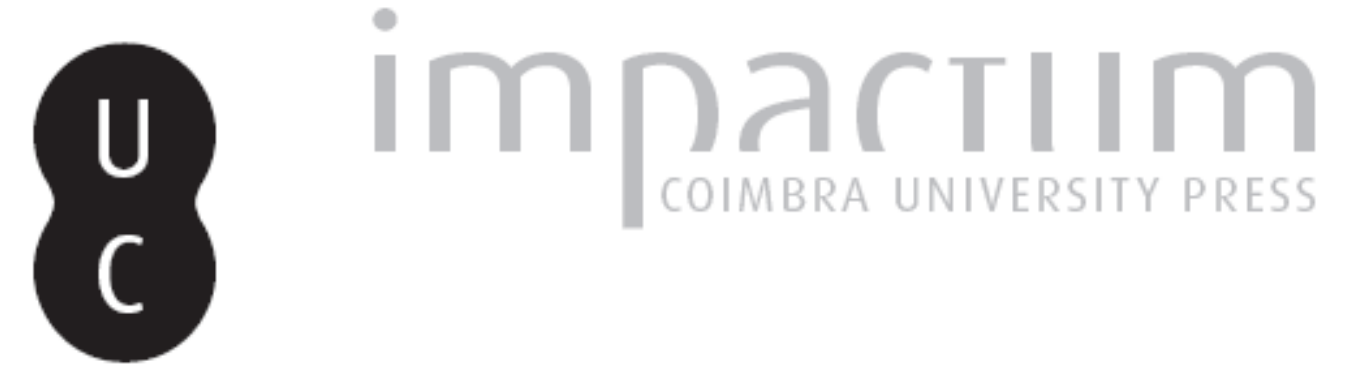

\title{
Ecossistemas de profundidade, AMPs oceânicas, plataforma continental além das 200mn e pioneirismo português
}

Autor(es): $\quad$ Ribeiro, Marta Chantal; Santos, Ricardo Serrão

\section{Publicado por: CEDOUA}

URL persistente:

URI:http://hdl.handle.net/10316.2/40029

DOI:

DOI:https://doi.org/10.14195/2182-2387_25_8

Accessed : $\quad$ 26-Apr-2023 14:00:07

A navegação consulta e descarregamento dos títulos inseridos nas Bibliotecas Digitais UC Digitalis, UC Pombalina e UC Impactum, pressupõem a aceitação plena e sem reservas dos Termos e Condições de Uso destas Bibliotecas Digitais, disponíveis em https://digitalis.uc.pt/pt-pt/termos.

Conforme exposto nos referidos Termos e Condições de Uso, o descarregamento de títulos de acesso restrito requer uma licença válida de autorização devendo o utilizador aceder ao(s) documento(s) a partir de um endereço de IP da instituição detentora da supramencionada licença.

Ao utilizador é apenas permitido o descarregamento para uso pessoal, pelo que o emprego do(s) título(s) descarregado(s) para outro fim, designadamente comercial, carece de autorização do respetivo autor ou editor da obra.

Na medida em que todas as obras da UC Digitalis se encontram protegidas pelo Código do Direito de Autor e Direitos Conexos e demais legislação aplicável, toda a cópia, parcial ou total, deste documento, nos casos em que é legalmente admitida, deverá conter ou fazer-se acompanhar por este aviso.

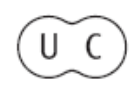




\section{RevCEDöUA}

N. ${ }^{0} 25$ _ Ano XIII_ 1.10

> Doutrina

Breve apontamento sobre a natureza jurídico-lributária da 'taxa'

sobre as lâmpadas de baixa eficiência energética

José Eduardo F. Dias

Joana Duarte Costa

A criaç̦ão de AMPs nas zonas da plataforma conlinental situadas além das 200 mn: Direito do Mar, CPLP e experiência portuguesa pós- 'hainbow'

Marta Chantal Ribeiro

A responsabilidade civil do estado brasileiro perante os riscos para o meio-ambiente do sequestro geológico de carbono

Lucas de Lima Carvalho

Da admissibilidade de meios extrajudiciais de resolução de confititos em matéria ambiental e urbanística - experiências presentes, possibilidades futuras

Cátia Marques Cebola

Concurso de Ideias e Estudos sobre a Revisão da Lei de Bases do Ambiente

Ana Cristina Vieira

> Jurisprudência

A desconsideração do nexo causal na responsabilidade civil ambiental

Neylene Fonseca

Recensões

Faclor Five: Transforming the Global Economu through 80\%

Improvements in Resource Productivity

Mariana Nicolau

Dossier

Ecossistemas de profundidade, AMPs oceânicas, plataforma continental além das 200mn e pioneirismo português

Marta Chantal Ribeiro

Ricardo Serrão Santos

Abstracts > Últimas Aquisições Bibliográficas

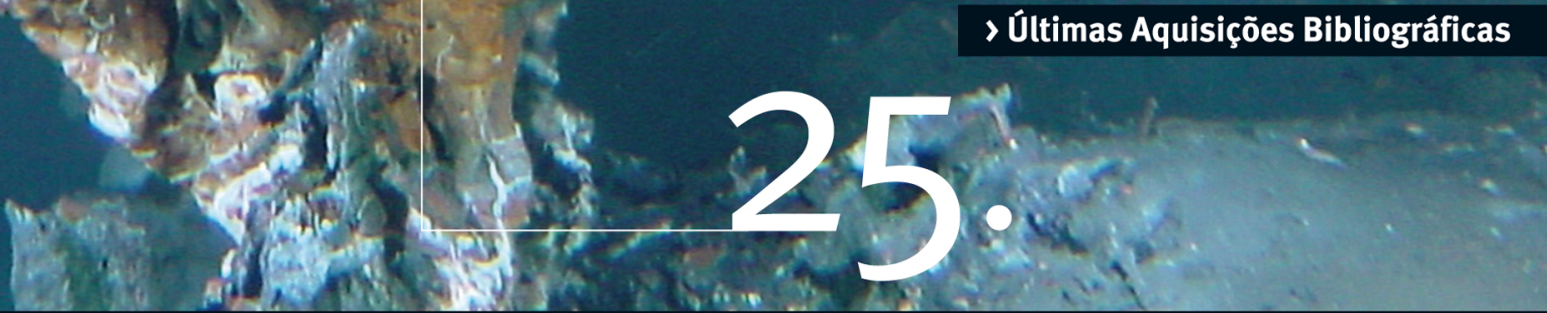

Revista do Centro de Estudos de Direito do Ordenamento, do Urbanismo e do Ambiente Urbanism, Territorial Order and Environment Studies Center Law Review 


\section{Ecossistemas de profundidade, AMPs oceânicas, plataforma continental além das 20omn e pioneirismo português}

I - Características dos ecossistemas de profundidade e razões para a sua protecção

1 - Conhecimento

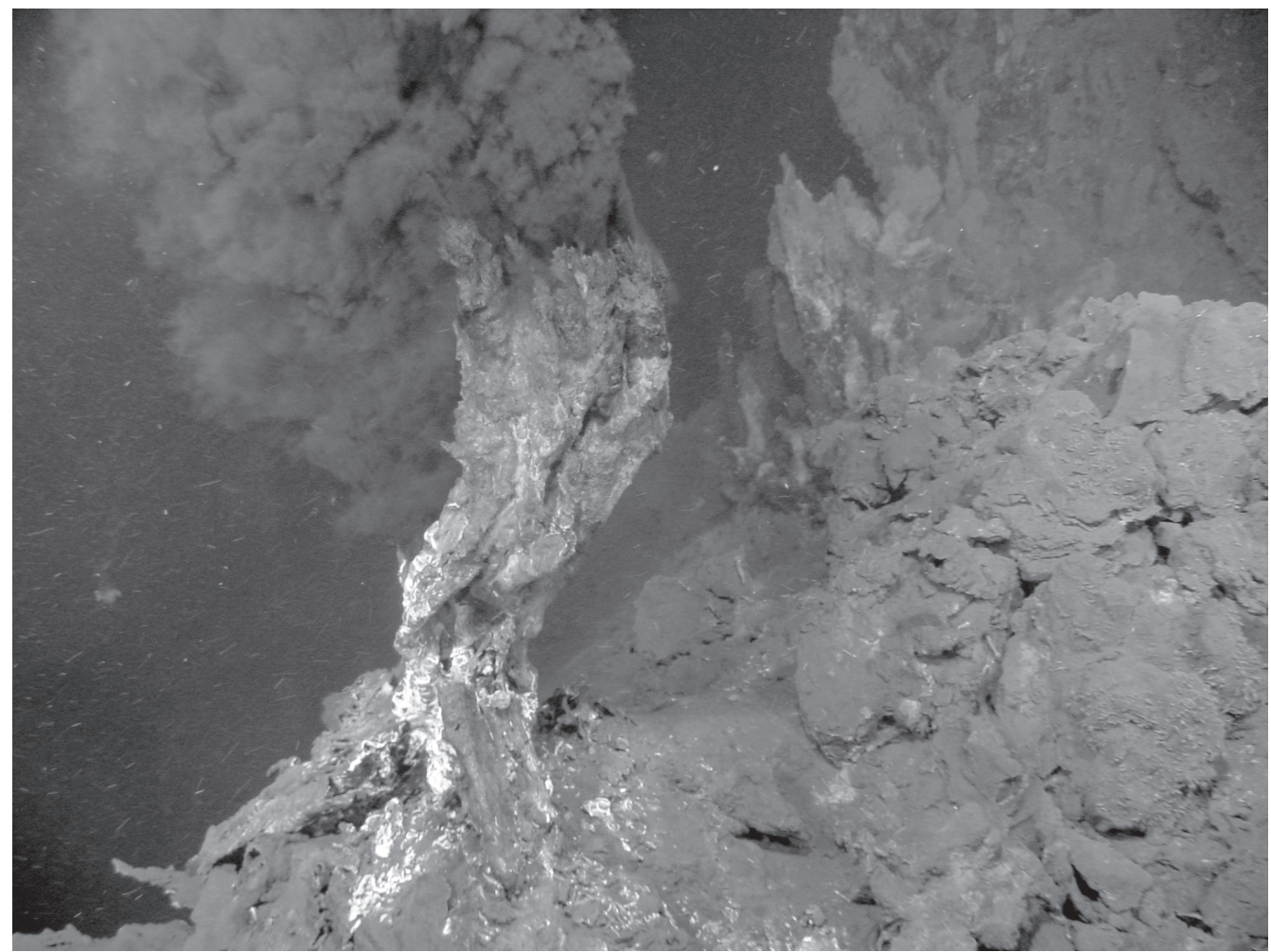

Legenda: Chaminé de fumo negro do campo hidrotermal Rainbow/Açores a 2300 metros de profundidade [Foto: (C) Missão SEAHMA- FCT-PDCTM/P/MAR/15281/1999) c/IFREMER].

1. Apesar de a exploração científica do mar profundo ser porventura a última das grandes proezas e desafios para o conhecimento no âmbito dos ecossistemas do planeta Terra, o crescente interesse político internacional relativamente a este assunto não assenta prioritariamente na aspiração a preencher lacunas do conhecimento científico. Esse interesse está 


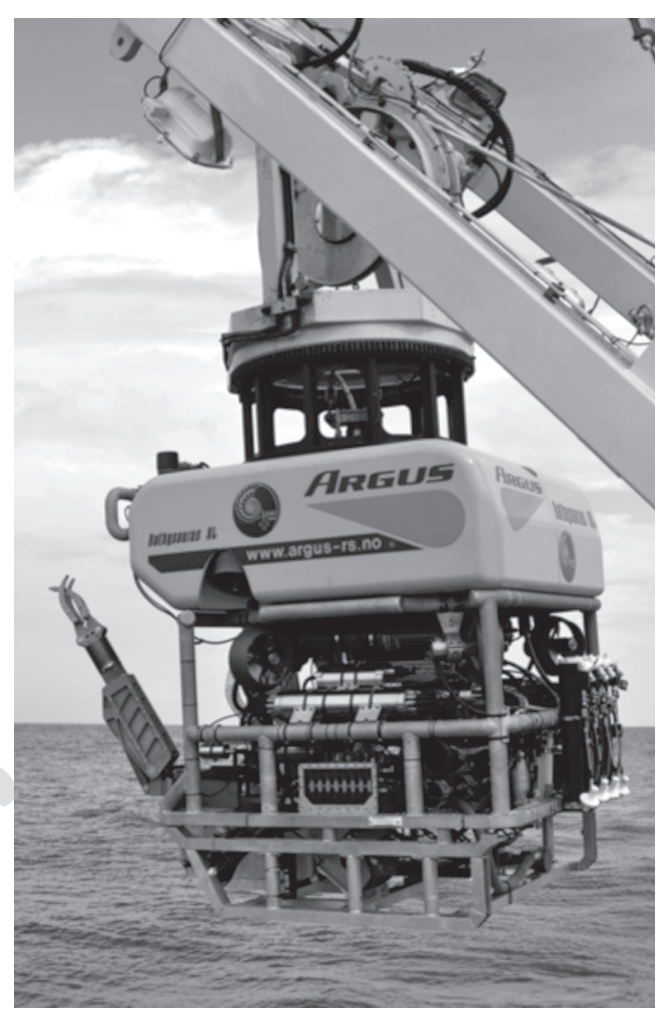

Legenda: ROV Luso 6000 (EMEPC) em operação nos Açores a bordo do NRP Gago Coutinho (Foto: Pedro Ribeiro /ImagDOP). relacionado com aspectos socioeconómicos e com desafios de governação muito concretos. Emerge, por exemplo, das consequências da migração da indústria pesqueira para águas profundas, em resposta aos colapsos em cadeia de recursos haliêuticos tradicionais e à propagação, a estes ambientes, da crise económica e ambiental da exploração pesqueira. Emerge, também, do interesse em explorar, no mar profundo, recursos energéticos, petrolíferos e minerais, para colmatar o esgotamento actual e futuro das jazidas em terra. Emerge, ainda, dos desafios relacionados com a necessidade de sequestrar $\mathrm{CO}_{2}$, para mitigar os efeitos das mudanças globais. Emerge, por fim, das oportunidades para as ciências biotecnológicas, que procuram novas moléculas e novos princípios activos oriundos de micro-organismos (bactérias, vírus...) ou invertebrados com benefício e interesse para as indústrias farmacêutica e de cosmética, por exemplo.

A estes aspectos associa-se a oportunidade de os Estados, dentro das condições previstas na Convenção das Nações Unidas sobre o Direito do Mar (artigos 76.ํ e seg., CNUDM), alargarem os seus direitos de soberania e poderes de jurisdição às espécies e habitats do solo e subsolo do mar profundo para além do limite da zona económica exclusiva (ZEE) e, também, a obrigação, resultante de diversas convenções internacionais, de os Estados contribuírem para assegurar a correcta gestão sustentável e protecção das espécies e dos habitats do mar profundo e do oceano aberto, dentro e fora da jurisdição nacional.

2. O estudo e novas descobertas ao nível dos ecossistemas do mar profundo situados na plataforma continental portuguesa, incluindo os que estão além das 200 milhas náuticas (mn), têm vindo a ser realizados com mais regularidade desde a década de noventa do século XX. Para isso tem contribuído a crescente capacidade de investigação do mar instalada na Europa (e nos EUA) e também o crescimento das capacidades em recursos humanos científicos em Portugal e sua internacionalização, dispersos por várias Universidades e Institutos de investigação. 
Deve sublinhar-se recentemente o incremento das capacidades nacionais com dois novos navios de investigação oceânica e um ROV (veículo robótico de operação remota) que pode operar até aos 6000 metros de profundidade ${ }^{1}$. No entanto, seria injusto não referir o trabalho realizado no século XIX e início do século XX, em águas portuguesas, em particular ao largo dos Açores, pelo Príncipe Alberto I do Mónaco, verdadeiro fundador da biologia do mar profundo.

No espaço marinho 'português' têm especial importância a dorsal Atlântica com campos hidrotermais, os montes submarinos, os corais de água fria e as agregações de esponjas. 0 processo de descoberta destes redutos de biodiversidade é permanente, continuando a encontrar-se, por exemplo, novos campos hidrotermais na Região Autónoma dos Açores, ao longo da componente sul da dorsal média atlântica desta região. Em boa verdade, considerando o vasto espaço marinho que está sob soberania ou jurisdição do Estado português - o maior no contexto local da União Europeia - e, até ao presente, o comparativamente modesto investimento no conhecimento da biodiversidade marinha em Portugal, há um longo trabalho de exploração e estudo pela frente. A afirmação vale para as zonas costeiras, mas é ainda mais pertinente no que toca as zonas oceânicas, cujos ecossistemas apresentam características muito distintas, sendo apenas os de profundidade - também há os de 'mar aberto' - objecto deste dossier. Por outras palavras, o texto dedica-se só às zonas oceânicas e, nestas, aos ecossistemas associados ao leito e subsolo marinhos (plataforma continental) mesmo que hajam relações de mútua influência com a coluna de água (integrada na zona económica exclusiva ou, se zonas da plataforma continental além das $200 \mathrm{mn}$, no alto mar). Porque aos termos nem sempre é atribuído o mesmo significado, quer dentro da mesma disciplina científica quer, aumentando os desvios, entre disciplinas diferentes, assume-se que as 'zonas costeiras' se estendem até ao limite exterior do mar territorial, correspondendo a $12 \mathrm{mn}$ contadas a partir das linhas de base, e que as 'zonas oceânicas' respeitam ao espaço marinho para lá do limite exterior do mar territorial. Dentro das 'zonas oceânicas' distinguem-se as que estão sob soberania ou jurisdição do Estado (em particular, a ZEE e a plataforma continental) e as que estão fora (o alto mar e a Área). Com todas as críticas de ordem não jurídica que possa merecer, a dicotomia «zonas costeiras v. zonas oceânicas» tem na base não critérios biológicos, ecológicos, geológicos ou de ordem política mas, antes, para simplicidade, as ficções legais estabelecidas pela CNUDM.

No presente, a Região Autónoma dos Açores e o Departamento de Oceanografia e Pescas da Universidade dos Açores têm-se empenhado no desenvolvimento de conhecimento associado à protecção e gestão sustentável dos ecossistemas de profundidade do mar 'português'. Algumas destas iniciativas têm sido inovadoras e fundadoras a nível internacional. São múltiplos os factores que têm condicionado este progresso e que o continuarão a estimular não só naquela região como também no continente e na Região Autónoma da Madeira. Evidencia-se a actividade relacionada com a protecção da biodiversidade do mar profundo no seio da Convenção OSPAR, o aprofundamento da Rede Natura 2000 no espaço marinho oceânico, a transposição da Directiva-Quadro 'Estratégia marinha' (2008/56/CE), a ambição de concretização de um planeamento espacial marinho baseado numa abordagem ecossistémica e, em geral, os compromissos políticos, nacionais e europeus, de investimento nas potencialidades do oceano, do qual é indissociável o conhecimento e protecção da biodiversidade. Todos os factores enunciados têm na sua raiz ou como ponderável o reconhecimento da importância da biodiversidade marinha para o equilíbrio e saúde do oceano e, por reflexo, do ambiente global.

${ }^{1}$ R. S. Santos, «O Conhecimento Científico do Mar», Nação e Defesa (Instituto de Defesa Nacional), 122 (4ª série), 2009, pp. 89-100. 


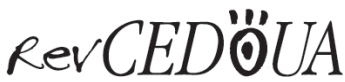

\section{> Dossier}

\section{2 - Descrição dos ecossistemas de profundidade mais importantes em Portugal}

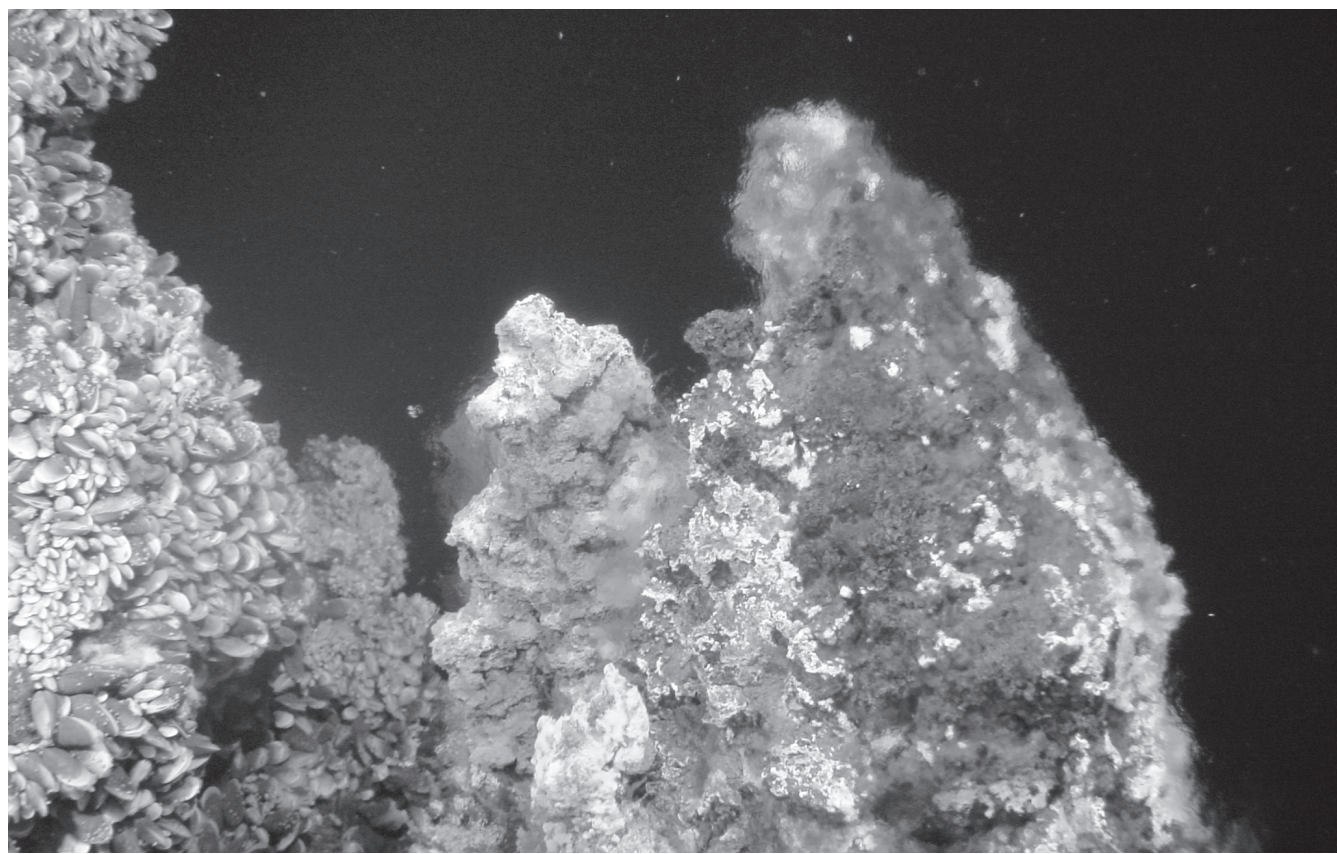

Legenda: Detalhe de uma chaminé do campo hidrotermal Lucky Strike/Açores a cerca de 1700 metros de profundidade, onde sobressai uma colónia de mexilhões (Bathymodiolus azoricus) [Foto: (@ Missão SEAHMA- FCT-PDCTM/P/ MAR/15281/1999) c/IFREMER].

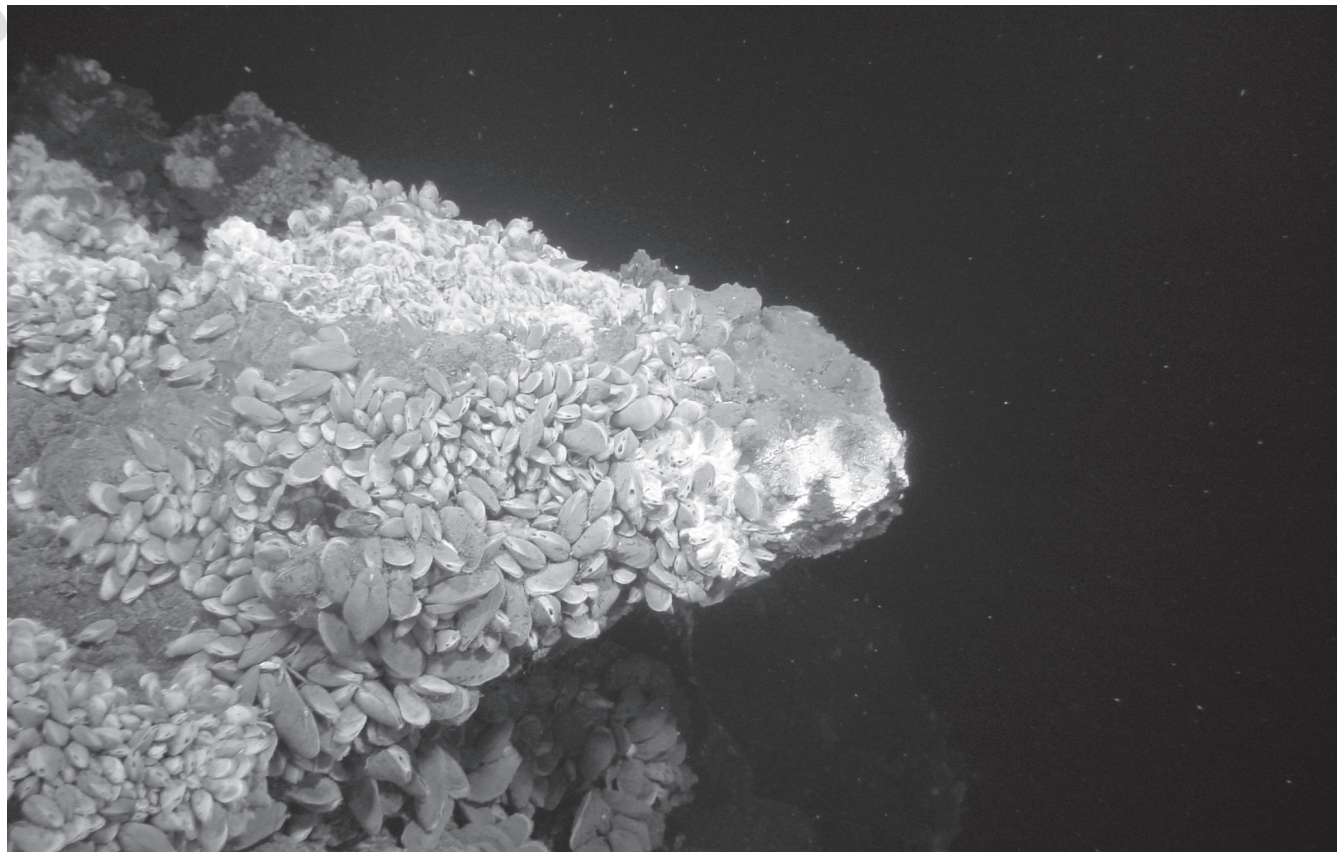

Legenda: Comunidade de mexilhões (Bathymodiolus azoricus) no campo hidrotermal Lucky Strike/Açores a cerca de 850 metros de profundidade [Foto: (C Missão SEAHMA- FCT-PDCTM/P/MAR/15281/1999) c/ IFREMER].

○” 
1. Os campos hidrotermais são ecossistemas singulares que estão relacionados com a tectónica de placas, mais precisamente com a zona de separação das placas. Nestas zonas o magma ascende a temperaturas de cerca $+1200^{\circ} \mathrm{C}$ que, em contacto com as águas frias, consolida e forma nova crosta fracturada, conhecida como dorsais e cristas. A água do mar, por movimentos de convexão, circula na nova crosta e aquece em contacto com a câmara magmática. De facto, os fundos oceânicos estão fracturados e essas extensas e amplas fracturas permeiam uma dinâmica circulação das águas oceânicas. Essa água quente, anóxica (sem oxigénio), ao ascender até à superfície da crosta, transporta gases tais como o dióxido de carbono, o hidrogénio, o metano, o sulfureto de hidrogénio, arrastando consigo vários minerais como o ferro, o cobre, o zinco, o chumbo, o mercúrio, etc. Ao entrar em contacto com a água do mar fria, rica em oxigénio, vários minerais precipitam, formando assim as típicas chaminés que caracterizam os ditos campos. Os fluidos que saem dessas chaminés podem atingir os $+350^{\circ}$ C. São os compostos reduzidos (fonte de energia) e o dióxido de carbono transportados por estes fluidos que permitem que microrganismos quimiossintéticos produzam matéria orgânica. À volta destas chaminés estabelecem-se autênticos oásis de vida que tiram partido desta fonte de alimento. A grande maioria não se encontra em mais nenhum ambiente marinho, são pois considerados endémicos e/ou especializados destes ambientes, tóxicos, dispersos e instáveis. 0 interesse científico despertado por estes ecossistemas caracterizados pela ausência de luz, elevada pressão, actividade vulcânica, baixa taxa de oxigénio, gradientes de temperatura que podem atingir os $+35^{\circ} \mathrm{C}$, fluidos com baixo $\mathrm{pH}$ e altamente ricos em metais pesados, chaminés ricas em importantes minerais - é enorme. Estes ecossistemas são uma janela para a origem e evolução da vida². 0 seu estudo tem valor potencial para a indústria biotecnológica (extremo-enzimas, desintoxicação, mecanismos de reparação de lesões do $A D N$, etc. ${ }^{3}$ ) e para o estudo da génese de depósitos de minerais em terra. Para além disso, e apesar da profundidade a que se encontram, são visualmente espectaculares e geram interesse público alargado 4 .

2. Os montes submarinos são, como o nome indica, elevações montanhosas, geralmente de origem vulcânica e que se elevam a mais de mil metros acima do solo marinho, mas permanecendo submersos abaixo da superfície dos oceanos. Os montes submarinos podem ser de formas variadas, mas a forma mais comum é a cónica com uma base circular ou elíptica.

\footnotetext{
${ }^{2}$ Luis Delaye \& Antonio Lazcano, "Prebiological evolution and the physics of the origin of life", Physics of Life Reviews, 2, 2005, pp. 47-64; Koichiro Matsuno \& Atsushi Nemoto, "Quantum as a heat engine - the physics of intensities unique to the origins of life", Physics of Life Reviews, 2, 2005, pp. 227-250.

${ }^{3}$ Christopher C. Thornburg, T. Mark Zabriskie \& Kerry L. McPhail, "Deep-Sea Hydrothermal Vents: Potential Hot Spots for Natural Products Discovery?", Journal of Natural Products, 73, 3, 2010, pp. 489-499.

${ }^{4}$ Joe Macinnis, James Cameron's Aliens of the Deep: Voyages to the Strange World of the Deep Ocean, National Geographic, 2005, 192pp.
} 


\section{RerCEDöUA}

$>$ Dossier

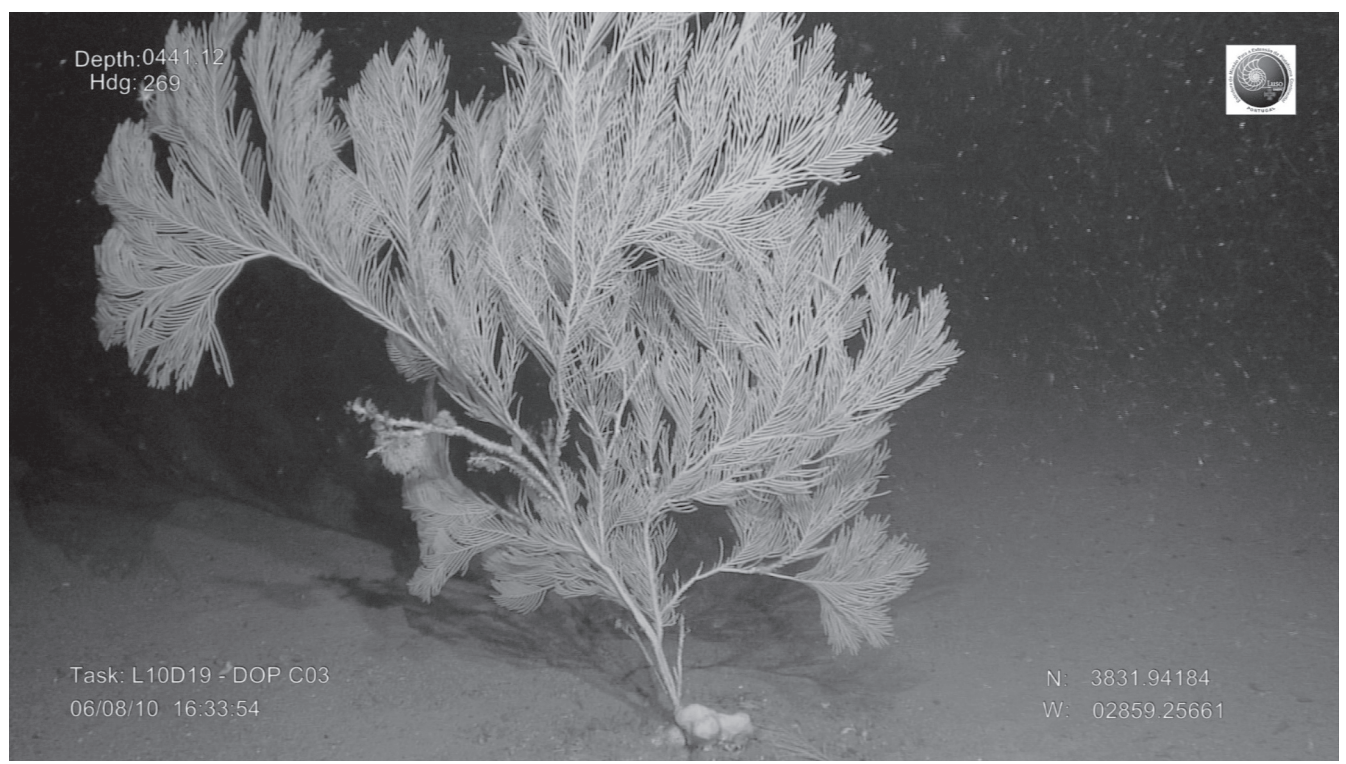

Legenda: Gorgónia (ou coral negro) do género Leiopathes fotografada no monte submarino Condor em Agosto de 2010 durante a missão CoralFish, conduzida pelo Departamento de Oceanografia e Pescas da Universidade dos Açores a bordo do NRP Gago Coutinho e utilizando o ROV Luso da EMEPC.

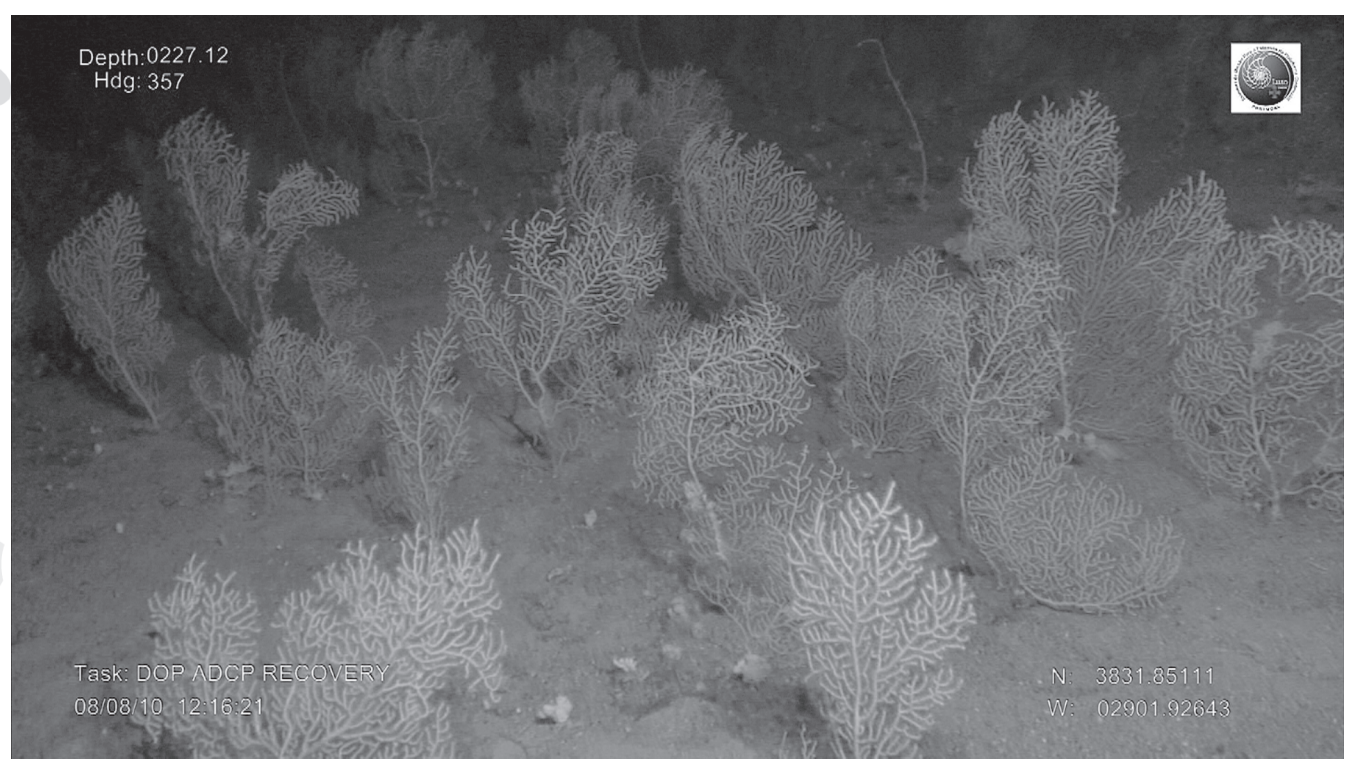

Legenda: Jardim de corais no monte submarino Condor fotografados em Agosto de 2010 durante a missão CoralFish, conduzida pelo Departamento de Oceanografia e Pescas da Universidade dos Açores a bordo do NRP Gago Coutinho 


\section{RerCED光UA

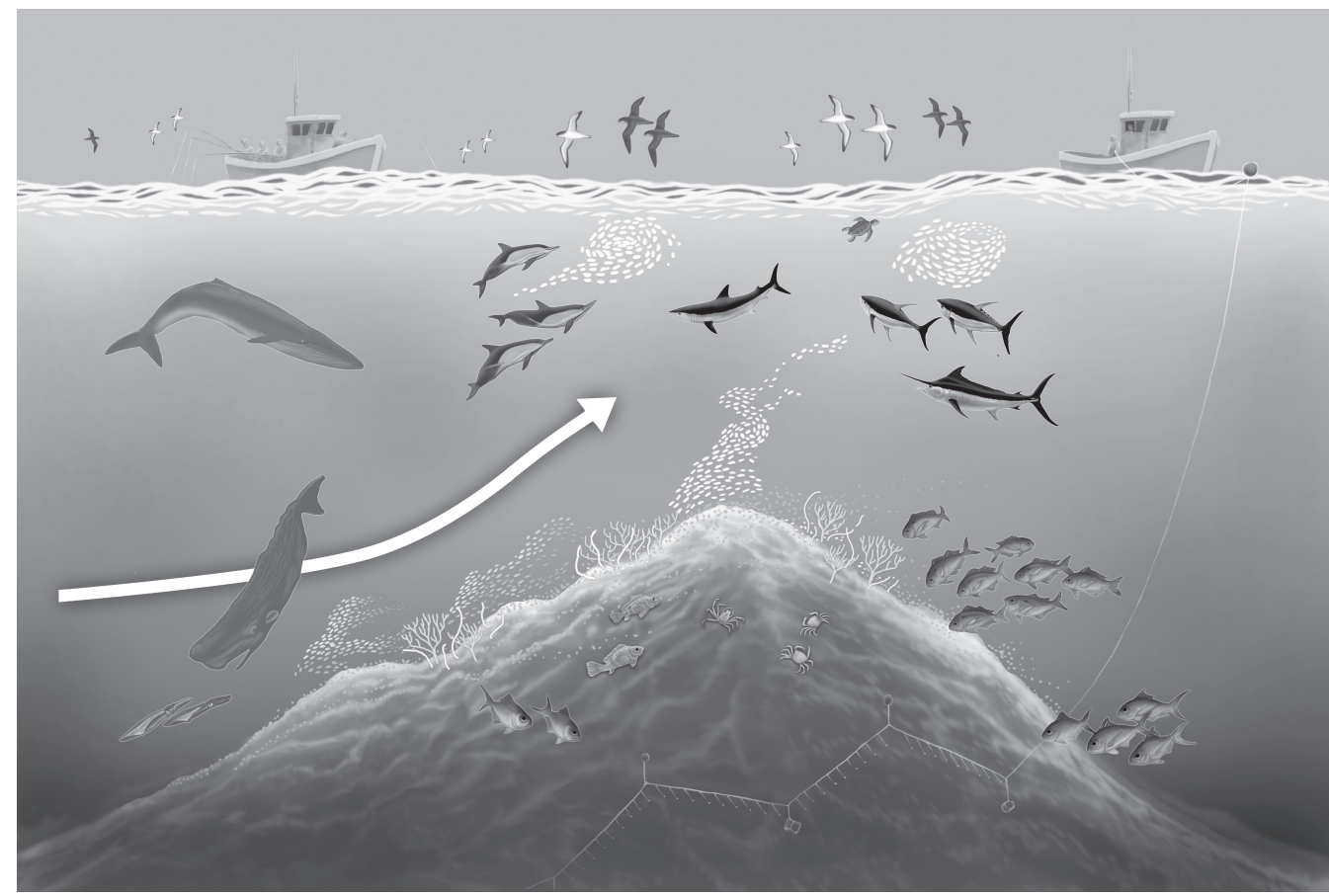

Legenda: Representação artística de um monte submarino. Os montes submarinos têm uma biodiversidade assinalável, quer em espécies bênticas e demersais, quer em espécies pelágicas e como tal atraem também actividades de pesca, aqui representadas pelas pescas artesanais dos Açores (Les Gallagher @ fishpics \& ImagDOP).

O relevo descrito contrasta com o ambiente plano das planícies abissais e cria efeitos particulares na circulação oceânica circundante, dando por vezes origem a correntes circulares persistentes, conhecidas como colunas de Taylor, que capturam biomassas e mantêm produtividades primárias mais localizadas e persistentes. Estes fenómenos contribuem, por sua vez, para o aumento da complexidade trófica associada aos montes submarinos. A sua estrutura rochosa favorece o crescimento de várias espécies de filtradores como os corais frios e gorgónias, que formam recifes e jardins exuberantes, e as esponjas, que formam extensas agregações. Estes habitats constituem, por seu lado, a base para a existência, refúgio e alimentação de diversas espécies de moluscos, crustáceos e peixes (macro-espécies) que estabelecem comunidades complexas. Os montes submarinos atraem também numerosas espécies pelágicas, como cetáceos, atuns, tubarões, espadartes e aves que tiram proveito da produtividade acrescida ali existente. Algumas espécies de peixes de profundidade, muitas delas com elevado interesse comercial, especializaram-se a viver junto aos montes submarinos onde formam agregações. No entanto, estas espécies são particularmente vulneráveis à pesca devido às suas longevidade, maturação tardia, crescimento lento e baixa mortalidade natural. Muitas espécies de corais frios são também extremamente vulneráveis e pouco resilientes, dada a sua grande longevidade, que pode atingir os 4000 anos 5 .

${ }^{5}$ T. J. Pitcher, Morato, P. J. B. Hart, M. R. Clark, N. Haggan \& R.S. Santos (Eds.), Seamounts: Ecology, Fisheries and Conservation, Oxford, UK; lowa, USA; Victoria, Australia, Blackwell Publishing, 2007, xxvi + 527pp. 


\section{RerCED光UA}

$>$ Dossier

3. As dorsais oceânicas com campos hidrotermais, os montes submarinos, os recifes e os jardins de corais frios, e as agregações de esponjas estão, pela sua importância e vulnerabilidade, classificados como habitats prioritários em numerosas convenções e directivas internacionais (v.g., Convenção OSPAR 6 e Convenção sobre a Diversidade Biológica).

\section{II - 0 meio de protecção privilegiado: 'áreas marinhas protegidas'}

\section{1 - Instrumentos de protecção dos ecossistemas}

Importantes ecossistemas de profundidade descobertos em Portugal estão qualificados como únicos, raros e/ou vulneráveis, constituindo a sua protecção uma prioridade na estratégia global de conservação dos oceanos. Esta questão é pacífica. Ao contrário, para cada situação, nem sempre existe acordo quanto aos instrumentos de protecção adequados. A divergência muitas das vezes explica-se mais pelo confronto de interesses antagónicos (sócio-económicos, políticos versus ambientais) do que por razões objectivas, exclusivamente centradas no melhor resultado ambiental. Assim, se no meio científico há um entendimento preponderante de que as áreas marinhas protegidas (AMPs), sobretudo se concebidas em 'rede', são o instrumento mais completo e eficaz para prossecução do desígnio da preservação dos ecossistemas marinhos, os utilizadores (e, no contexto internacional, certos Estados) tendem a dar corpo a medidas avulsas e sectoriais como uma solução bastante. Consoante os impactos negativos a eliminar ou prevenir, entre estas medidas figuram as áreas de encerramento à pesca, a proibição do uso de certas artes de pesca (v.g., redes de arrasto) em determinadas áreas, a designação de 'áreas a evitar' para todos ou alguns navios comerciais, a designação de 'zonas marinhas particularmente sensíveis' também em sede da navegação, a regulação e controlo da condução de projectos de investigação científica marinha, realizados em prol do bem comum ou com objectivos comerciais, lucrativos (v.g., prospecção de petróleo; bioprospecção para aproveitamento de recursos genéticos). Conforme as hipóteses, caberá ao Estado português, à União Europeia, a organismos regionais de pesca ou à Organização Marítima Internacional aprovar as medidas pretendidas.

Hoje o movimento internacional em prol da criação de AMPs, nem que apenas justificadas pelo princípio da precaução, favorece a superação de medidas erráticas e a aprovação de regimes 'omnicompreensivos', típicos daquele instrumento com vocação globalizante. Por conseguinte, assiste-se a uma alteração do paradigma, privilegiando-se uma maior racionalidade e coerência na utilização das medidas avulsas disponíveis, ponderadas e avaliadas agora no seu conjunto dentro da figura jurídica da 'área marinha protegida' e dos objectivos específicos estabelecidos em cada caso.

O conceito de área marinha protegida aqui subentendido é o mais próximo da sua concepção originária, isto é, a de um instrumento jurídico cuja finalidade primária é a protecção da biodiversidade marinha e dos ecossistemas, e através do qual é criado um regime global, regulador, por intermédio de proibições e condicionamentos, de todas as actividades humanas conflituantes com os objectivos estabelecidos. Defende-se que as AMPs oferecem um maior potencial para dar visibilidade ao cuidado a desenvolver na preservação dos ecossistemas e, por isso, influenciam o cumprimento voluntário das medidas restritivas adoptadas.

Pese embora a importância contemporaneamente atribuída às AMPs, há, todavia, situações nas quais a adopção de simples medidas avulsas poderá ser, de facto, suficiente atendendo aos objectivos ambientais em vista (v.g., proibição do uso de artes de pesca de

${ }^{6}$ R. S. Santos, A. Colaço, “Background Document for Oceanic ridges with hydrothermal vents/fields”, OSPAR Commission, Biodiversity Series, Publication No. 490, 2010, 17pp.; R. S. Santos, F. Tempera \& T. Morato, "Background Document for Seamounts”, OSPAR Commission, Biodiversity Series, Publication No. 492, 2010, 28pp. 


\section{RerCED光UA \\ $>$ Dossier}

fundo numa vasta área rica em corais de água fria e esponjas). Além disso, no estádio actual de profundo atraso na criação de AMPs oceânicas, o recurso a medidas avulsas reveste-se de um significado extremo como instrumentos provisórios, por assim dizer, 'preventivos'. Sem isso correr-se-á o risco da degradação ou mesmo da destruição dos ecossistemas e da inutilidade da declaração formal da área marinha protegida.

\section{2 - Exemplos de medidas avulsas adoptadas para protecção de ecossistemas de pro- fundidade portugueses}

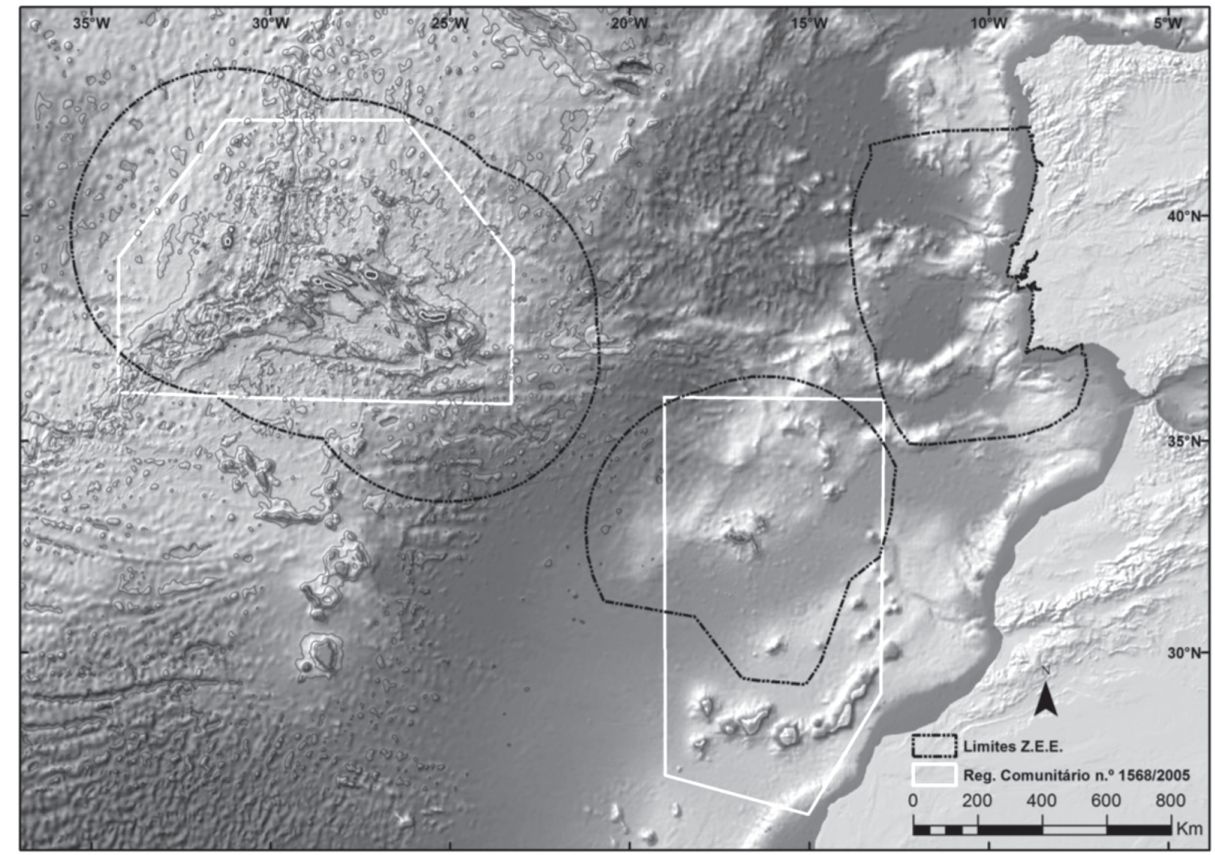

Legenda: Representação das ZEEs de Portugal Continental, Açores e Madeira (linhas escuras ponteadas) e das áreas delimitadas pelo Regulamento comunitário nํ1568/2005, o qual abrange os Açores, a Madeira e as Canárias (linhas brancas). (R Medeiros (OImagDOP)

Em Portugal, no contexto das regiões, existem alguns exemplos que ilustram as situações descritas no parágrafo anterior.

O fundo marinho dos Açores e da Madeira é rico em corais de água fria sendo que os recifes e os jardins se apresentam distribuídos por uma área muito ampla. Para os proteger do impacto negativo da pesca demersal, no seguimento de uma iniciativa que envolveu a Região Autónoma dos Açores, o Conselho da União Europeia, em 20 de Setembro de 2005, aprovou o Regulamento comunitário n. ${ }^{1568 / 2005}$, pelo qual se proíbe a utilização naquela área de um conjunto de artes de pesca de profundidade (v.g., redes de emalhar, enredar e de arrasto pelo fundo ou similares).

Os motivos que levaram à adopção deste Regulamento excedem, porém, as de protecção pura e simples dos recifes e dos jardins de corais e o facto reflectiu-se na delimitação geográfica final. O legislador teve também por intenção prevenir a degradação ou destruição de outros ecossistemas importantes, em especial porque alguns deles já estavam então apontados como zonas de futuras AMPs (assinaladamente, da Rede OSPAR e/ou da Rede Natura 
2000). Assim acontecia, nos Açores, por exemplo, com os campos hidrotermais Lucky Strike, Menez Gwen e Rainbow (este situado além das 20omn) e com o monte submarino Sedlo.

Com um resultado semelhante ao do Regulamento comunitário, os montes submarinos Altair e Antialtair (Açores), assim como a Mid-Atlantic Ridge North of the Azores, todos além das $200 \mathrm{mn}$, beneficiam dos encerramentos à pesca de fundo determinados pela Comissão de Pescas do Atlântico Nordeste (NEAFC), em vigor desde Abril de 2009 e até, pelo menos, 2012. Esta protecção justificou-se pela raridade e vulnerabilidade dos ecossistemas e foi reforçada pelo facto de no âmbito da Convenção OSPAR surgir a possibilidade de ali serem criadas AMPs, o que se veio a concretizar em 2010, por iniciativa portuguesa.

\section{III - Quadro legal aplicável às AMPs oceânicas dentro da soberania ou jurisdição do Estado português}

A criação de AMPs oceânicas, incluindo nas zonas da plataforma continental situadas além das 200mn, por reflexo da esperança nelas votada internacionalmente, transformou-se num tema emergente neste início do século XXI. Em Portugal esta questão teve, em termos legais, uma repercussão célere, pela razão de o nosso país incorporar o maior espaço marinho dentro do contexto local da União Europeia conjugada com a existência de ecossistemas cuja protecção é reclamada na esfera mundial. De um modo genérico, é correcto afirmar-se que Portugal se dotou dos meios jurídicos necessários à criação de AMPs oceânicas.

Do ponto de vista internacional, Portugal é parte da Convenção das Nações Unidas sobre o Direito do Mar, de 1982, da Convenção sobre a Diversidade Biológica, de 1992, e da Convenção para a Protecção do Meio Marinho do Atlântico Nordeste (Convenção OSPAR), de 1992, inclusive do seu Anexo V, relativo à Protecção e Conservação dos Ecossistemas e da Diversidade Biológica das Zonas Marítimas (1998), sendo este o anexo relevante em matéria de AMPs. A CNUDM é a base fundamental a partir da qual os regimes legais relativos às AMPs devem ser interpretados, num processo de mútua influência. 0 imbróglio de mais difícil deslinde para garantia do estabelecimento de AMPs efectivas e eficazes relaciona-se com a articulação dos poderes do Estado costeiro com os direitos dos Estados terceiros. No terreno da União Europeia, as AMPs oceânicas estão, sobretudo após 2007, e observações críticas à parte7, enquadradas no regime da Rede Natura 2000 (Directivas Aves e Habitats, transpostas pelo Decreto-Lei n.ำ 140/99, de 24 de Abril) e, de maneira indirecta, na Directiva-Quadro 'Estratégia

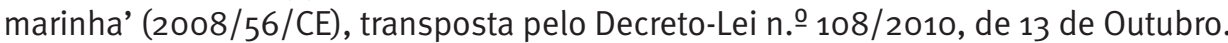

No plano interno, a legislação portuguesa dá, com menos ou mais clareza, fundamento legal à criação de AMPs oceânicas, ainda que a sua operacionalização concreta enfrente por hora alguns obstáculos (v.g., problemas ligados à gestão e ordenamento do espaço marinho).

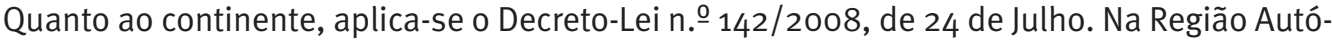
noma dos Açores, basicamente, o Decreto Legislativo Regional n. 0 15/2007/A, de 25 de Junho. Na Região Autónoma da Madeira o quadro legal é menos óbvio, resultando de uma aplicação do regime do Parque Natural da Madeira (Decreto Regional n.. 14/82/M, de 10 de Novembro, e Decreto Regulamentar Regional n.. 13/93/M, de 25 de Maio), tendo na base a legislação nacional sucessiva relativa às áreas protegidas (hoje, o Decreto-Lei n. ${ }^{\circ} 142 / 2008$, artigo $54 .{ }^{\circ}$ ).

${ }^{7}$ Marta Chantal Ribeiro, «Rede Natura 2000: os desafios da protecção da biodiversidade marinha no dealbar do século XXI», Temas de Integração, 25, 2008, pp. 165-233. 


\section{IV - 0 exemplo português na criação de AMPs oceânicas}

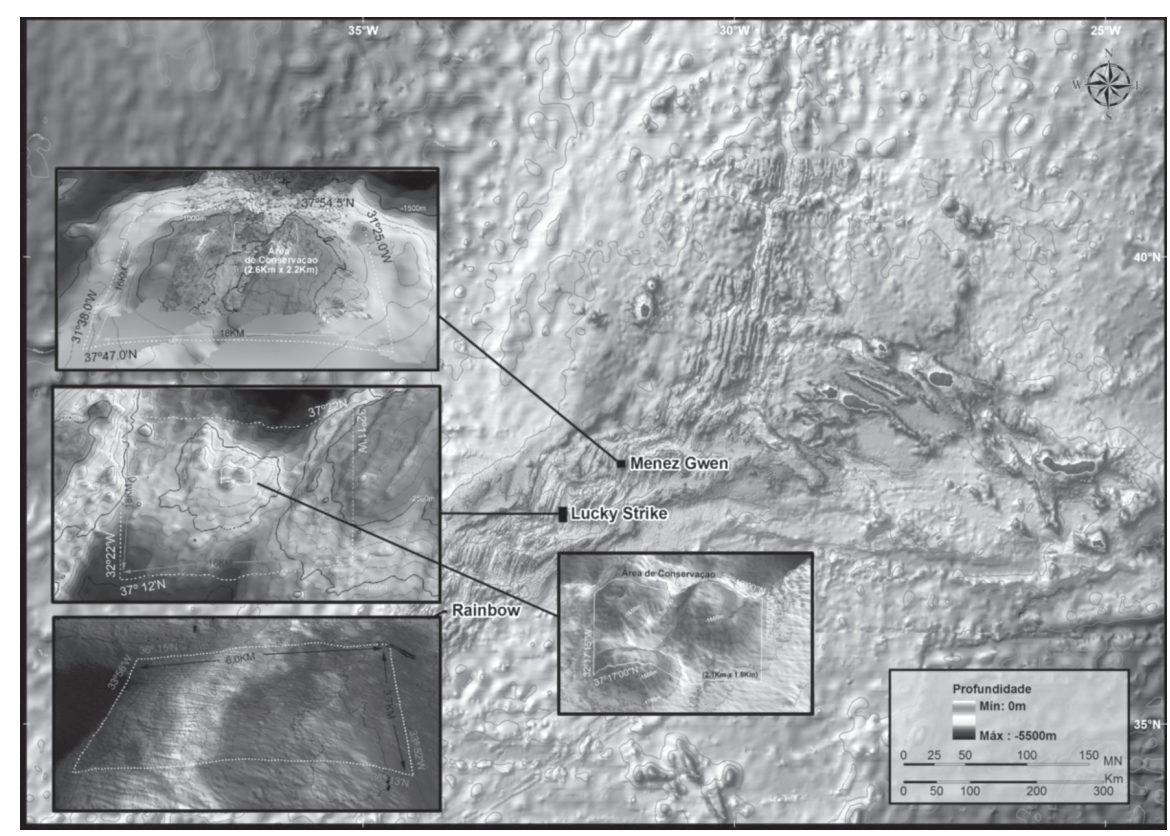

Legenda: Localização dos três principais campos hidrotermais dos Açores e áreas marinhas protegidas (F Tempera \& R Medeiros (CImagDOP).

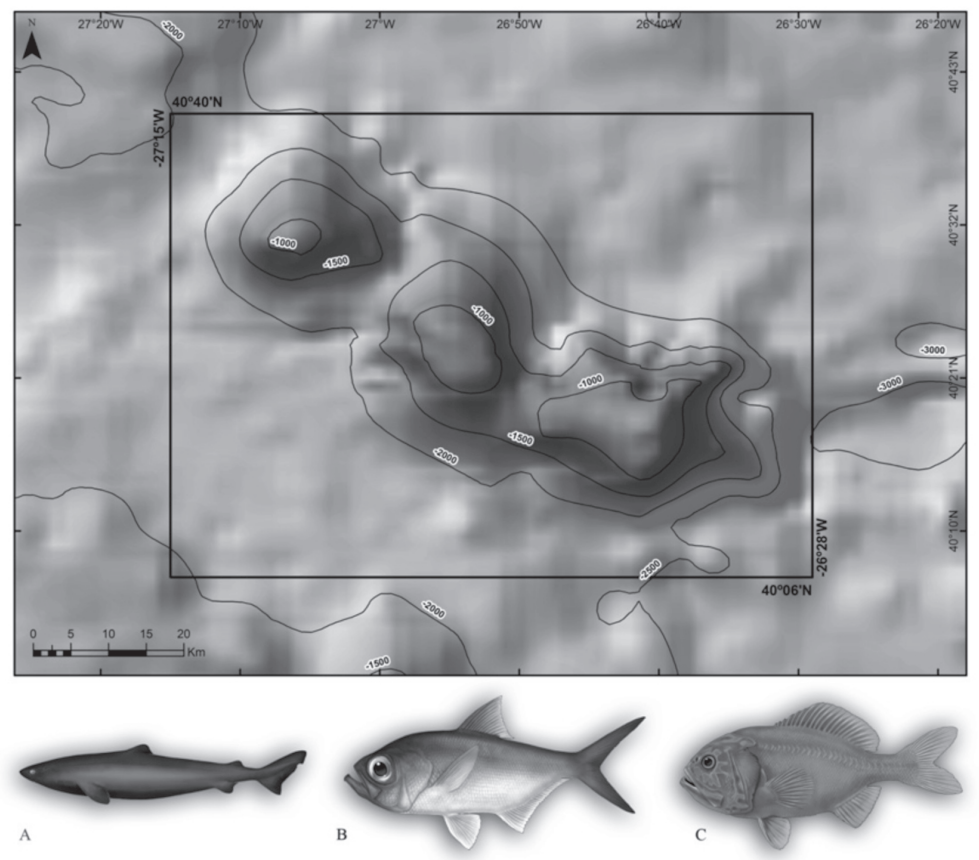

Legenda: Área Marinha Protegido do Monte Submarino Sedlo (FTempera \& R Medeiros @ImagDOP). Ilustrações de três espécies de peixes que ali ocorrem, as quais são consideradas prioritárias em termos de conservação: A - Centroscymnus coelolepis - tubarão português; B - Beryx splendens - alfonsino; C - Hoplostethus atlanticus - peixe relógio (ilustrações de Les Gallagher (c) fishpics \& ImagDOP). 


\section{$\operatorname{RerCEDळ̋UA~}$}

$>$ Dossier

\section{1 - Progressos na Rede Natura 2000}

Os desenvolvimentos ocorridos em 2007 com o objectivo de alargar o alcance da Rede Natura 2000 no espaço marinho favoreceram a selecção das áreas de alguns ecossistemas de profundidade - campos hidrotermais Lucky Strike e Menez Gwen -, entretanto reconhecidos como 'sítios de importância comunitária', futuras 'zonas especiais de conservação' (Decisão da Comissão Europeia n.ำ 2009/1001/UE, de 22 de Dezembro). Os campos estão situados dentro dos limites da ZEE da região dos Açores. O Lucky Strike localiza-se a cerca de 1700 metros de profundidade e a AMP ocupa uma área de 192 Km2. O Menez Gwen localiza-se a cerca de 850 metros de profundidade e a AMP ocupa uma área de 95,2 Km2.

Também naquela região, embora só até à batimétrica dos -200 metros, integram a Rede Natura 2000 os seguintes ecossistemas oceânicos: o Banco D. João de Castro (ZEE) e os ilhéus das Formigas/Recife Dollabarat, sendo que este último complexo é uma AMP que inclui profundidades até pelo menos -1600 metros. Note-se que os ilhéus das Formigas/ Recife Dollabarat estão a cerca de $20 \mathrm{mn}$ da ilha de Santa Maria e a cerca de $34 \mathrm{mn}$ da ilha de São Miguel, mas em mar territorial devido à existência dos ilhéus.

A atribuição a Portugal do qualificativo de 'pioneiro' não se deve, todavia, a este resultado, ainda que notável, mas, sim, à iniciativa, sem paralelo, de, por impulso da actuação empreendida no âmbito da Convenção OSPAR, pretender criar AMPs para preservar diversos ecossistemas localizados na plataforma continental além das $200 \mathrm{mn}$, isto é, sob águas com o estatuto de alto mar. Realça-se que, na sequência da experiência obtida no quadro 'OSPAR', recentemente o campo hidrotermal Rainbow (Açores) foi seleccionado para a Rede Natura 2000, integrando a Lista Nacional de Sítios (Resolução do Conselho do Governo n. $\underline{0}$ $56 / 2010$ de 10 de Maio, Presidência do Governo Regional dos Açores), e existe a perspectiva de o monte submarino Josephine (entre o continente e a Madeira) vir a ser ponderado para o mesmo efeito. As duas zonas estão situadas na plataforma continental além das $200 \mathrm{mn}$.

\section{2 - 0 pioneirismo por conta da Rede de AMPs-OSPAR}

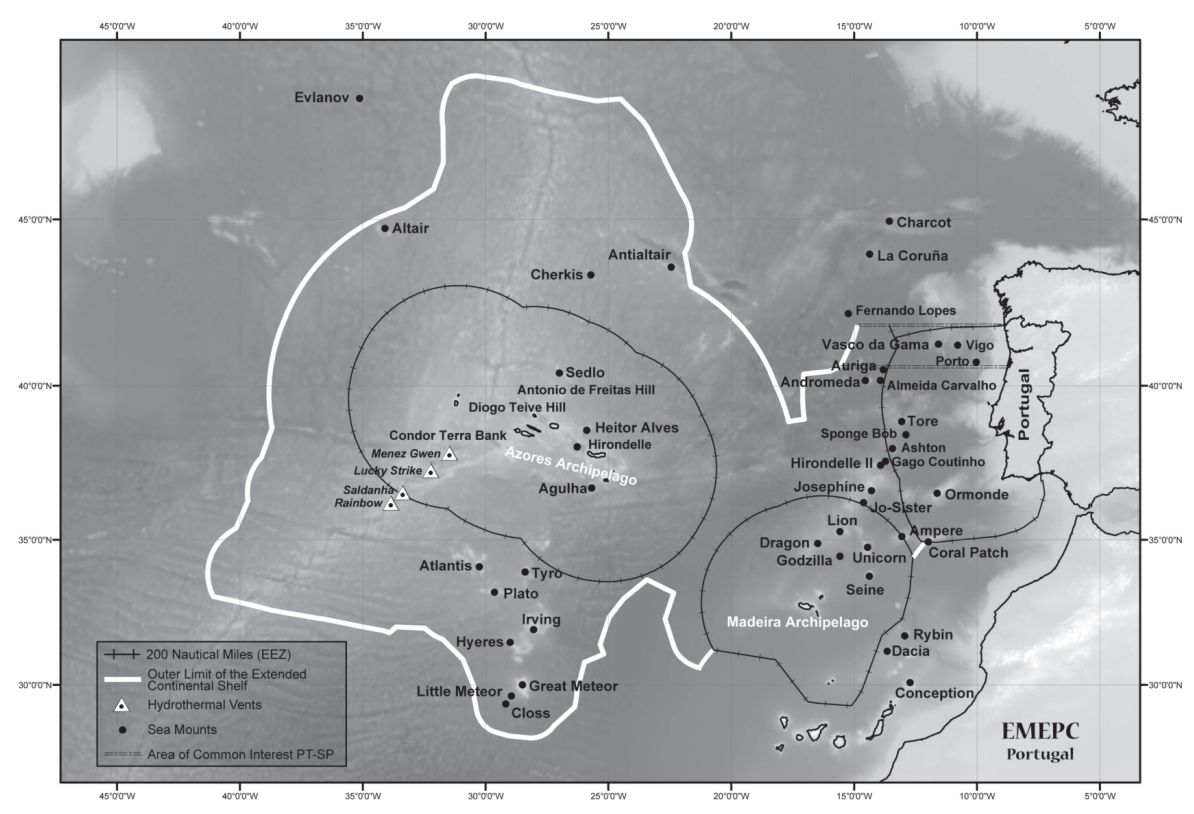

Legenda: Delimitação da zona económica exclusiva (linha preta) e perspectivas de fixação dos limites exteriores da plataforma continental além das 20omn (linha branca). Figura disponibilizada pela Estrutura de Missão para os Assuntos do Mar. 
1. A par da investigação dos ecossistemas oceânicos que vinha a ser realizada pelo Departamento de Oceanografia e Pescas da Universidade dos Açores, dois momentos decisivos de todo o processo ocorreram em 2005: um, relacionado com a definitiva criação, em Janeiro, da Estrutura de Missão para a Extensão da Plataforma Continental (EMEPC; Resolução do Conselho de Ministros n.. 9/2005; recentemente extinta, sendo a sua missão integrada na EMAM; Resolução do Conselho de Ministros n.ำ3/2011), o outro, atinente à aprovação pelo Governo, em Dezembro, da ratificação do Anexo V da Convenção OSPAR (Decreto n. $\stackrel{0}{7} / 2006$, de 9 de Janeiro), a qual se veio a concretizar em Fevereiro de 2006 (Aviso n.ำ 578/2006). Nesse ano ficou, portanto, firme o propósito de Portugal fazer uma submissão à Comissão de Limites da Plataforma Continental para definição do limite exterior da plataforma continental, quer dizer, além das 200mn, aproveitando-se os estudos nesse sentido que já vinham a ser efectuados. Por outro lado, a ratificação do Anexo $V$ e, por consequência, a aplicação imediata da Recomendação 2003/3, relativa a uma rede OSPAR de áreas marinhas protegidas, fizeram Portugal submergir num contexto onde se incentivava as Partes Contratantes a nomear AMPs para a rede OSPAR, havendo muito trabalho adiantado. No seio da OSPAR a relevância dada às zonas oceânicas tem sido uma constante, incluindo as que estão fora da jurisdição nacional (estas sob 'responsabilidade' da Comissão OSPAR) e pertençam à 'zona marítima OSPAR'.

2. A dinâmica ocasionada por este quadro levou a que Portugal protagonizasse a primeira nomeação para a Rede de AMPs-OSPAR, com os ilhéus Formigas/Recife Dollabarat (2005), e que em 2006 seleccionasse (além de duas zonas costeiras chamadas Canal Faial-Pico e llha do Corvo) as zonas de vários ecossistemas oceânicos, a saber: o Banco D. João de Castro e os campos hidrotermais Lucky Strike, Menez Gwen e Rainbow, sendo as AMPs oficialmente aceites pelas Partes Contratantes da Convenção OSPAR em 2007. Para o efeito em apreço, têm-se por equivalentes os termos 'selecção' e 'nomeação', mas o poder e o significado do acto em relação à fase subsequente do reconhecimento ou aceitação variam consoante o regime jurídico aplicável às redes (em relevo neste dossier, o regime da Rede Natura 2000 e o regime OSPAR e) e o contexto político envolvente.

A aceitação, em sede da OSPAR, da singular nomeação do campo Rainbow fez história, uma vez que o ecossistema se encontra além das 20omn numa zona pertencente à plataforma continental portuguesa, conforme os estudos efectuados garantiam. Além de ser o primeiro caso em todo o mundo de criação de uma AMPs nacional além das $200 \mathrm{mn}$, tendo a coluna de água, como foi já referido, o estatuto de alto mar, outro aspecto exemplar é o do reconhecimento da jurisdição do Estado português sobre o campo Rainbow acontecer numa altura em que só ainda havia o compromisso firme de Portugal apresentar uma submissão à Comissão de Limites da Plataforma Continental (materializou-se em 11 de Maio de 2009, com o n.. 44). 0 acontecimento envolveu posições interpretativas importantes da CNUDM e estimulou novos desenvolvimentos aos quais o nosso país ficará indissoluvelmente ligado ${ }^{8}$. 0 campo Rainbow localiza-se entre os 2270-2320 metros de profundidade e a AMP ocupa uma área de 250 X 6om (1,5Km2).

Em 2007 Portugal torna a nomear um ecossistema de profundidade da região dos Açores para a Rede de AMPs-OSPAR: o monte submarino Sedlo, situado dentro dos limites daZEE, aceite em 2008.

3. Recentemente, em 2010, desenrolou-se um outro conjunto de iniciativas que voltou a destacar o nome do nosso país na esfera internacional. Em Março de 2010 Portugal seleccionou mais quatro zonas da plataforma continental além das $200 \mathrm{mn}$ para a Rede de AMPs-OSPAR, relativas ao monte submarino Josephine, ao monte submarino Altair, ao monte submarino Antialtair e à Mid-Atlantic Ridge North of the Azores. Só o primeiro - Josephine - não está na região dos Açores, localizando-se entre o continente e a região da Madeira. 0 monte Josephine tem o cume mais elevado a cerca de 170m da superfície, ocupando a AMP uma

\footnotetext{
${ }_{8}^{8}$ Marta Chantal Ribeiro, «Rainbow, um exemplo mundial: a primeira área marinha protegida nacional em perspectiva
} sob águas do alto mar. À descoberta do tesouro do arco-íris», Revista do CEDOUA, 20, 2, 2007, pp. 47-86. 
área de $19.370 \mathrm{~km} 2$. O monte Altair tem os cumes mais elevados a profundidades de cerca de $3.635,8 \mathrm{~m}$ e a AMP ocupa uma área de $4.408,71 \mathrm{~km} 2$. O monte Antialtair tem os cumes mais elevados a profundidades de cerca de $890,6 \mathrm{~m}$ e a AMP ocupa uma área de $2.207,68 \mathrm{~km} 2$. A crista designada de Mid-Atlantic Ridge North of the Azores tem os cumes mais elevados a profundidades de cerca de $896,4 \mathrm{~m}$ e a AMP ocupa uma área de $93.568 \mathrm{~km} 2$.

As novas AMPs foram oficialmente aceites pelas Partes Contratantes em Outubro de 2010. O feito em si já era digno de atenção, mas foi acompanhado de uma novidade que tornou a distinguir Portugal entre os membros da Convenção OSPAR (ainda que a descontentamento de alguns), proporcionando uma projecção mundial da estrutura OSPAR e atribuindo-se ao nosso país o mérito de acolher uma interpretação vanguardista dos seus deveres enquanto Estado costeiro ("Portugal shows the way on high seas protected areas", Stephan Lutter, WWF, 24 de Março de 2010). Pelo que se segue.

Os ecossistemas em causa - montes submarinos e crista - implicam, pela sua natureza, uma inter-acção e inter-dependência com a coluna de água, pelo que a protecção isolada do leito marinho e subsolo não é suficiente para a preservação integral de todo o ecossistema. Por este motivo, na sequência de conversações entabuladas pelos peritos no âmbito da OSPAR, Portugal, também em Março de 2010, num acto novamente inédito, propôs à Comissão OSPAR a criação de AMPs na coluna de água (alto mar) sobrejacente às zonas do leito do mar e subsolo nomeadas por Portugal. A ideia foi a de materializar o conceito de «AMPs internacionais 'complementares' das AMPs nacionais», de um modo que tornasse explícito que a responsabilidade fundamental pela preservação dos ecossistemas pertence a Portugal, com as vantagens, mas também com os encargos, que isso traz. Em Outubro do mesmo ano, vencidas as resistências da Islândia, Noruega, Dinamarca e Reino Unido, as Partes Contratantes aprovaram a criação das quatro AMPs-OSPAR internacionais complementares, abrangendo a coluna de água sobrejacente às 'nossas' áreas. As dificuldades criadas por aqueles países provinham das discussões em torno de uma proposta delicada, mas lateral, de se conferir protecção global a uma extensa área marinha chamada Charlie-Gibbs Fracture Zone.

4. As realizações descritas incluem Portugal no grupo restrito de países que lidera a criação de AMPs oceânicas. Para já, no entanto, quanto à grande maioria das AMPs oceânicas, a única coisa que existe são declarações solenes da sua criação, estando todo o resto por fazer ou terminar (algumas já beneficiam de medidas avulsas, como se explica no ponto Il.2; no caso da AMP Formigas/Dollabarat há já medidas de gestão em vigor). A este respeito, são muitas as expectativas colocadas nos futuros planos de ordenamento do espaço marinho, em fase de discussão pública no continente e em elaboração nos Açores e na Madeira. Por outro lado, será interessante acompanhar o processo de adopção das medidas restritivas das actividades e usos humanos nas AMPs oceânicas, fundamentalmente nas situações em que Portugal não tem poder unilateral para agir. Mutatis mutandis, o mesmo se diga quanto às operações de fiscalização e sanção.

11 de Março de 2011

Marta Chantal Ribeiro Assistente da Faculdade de Direito da Universidade do Porto, membro do Centro de Investigação Jurídico-Económica; contacto: mchantal@direito.up.pt

Ricardo Serrão Santos Investigador Principal e Director do Departamento de Oceanografia e Pescas da Universidade dos Açores; contacto: ricardo@uac.pt 